\title{
Introduction: Social Media and Chinese Digital Diaspora in Australia
}

Haiqing Yu (RMIT) and Wanning Sun (UTS)

With the increasing number of PRC-born Chinese migrants in Australian and their active use of Chinese-language digital and social media in almost all aspects of their socioeconomic, political, and cultural lives, it is no surprise that attention to and debate on Chinese digital diaspora-diasporas organised around the Internet, social media, and other digital

platforms - has increased significantly. This special issue responds to and goes beyond such a debate in the Australian context. It includes four papers that critically engage with two key concepts, social media and Chinese digital diaspora. They examine the relation between Chinese migrants' engagement with social media, their participation in Australian public life, and their reconceptualisation of identity, community, and spatiality in the age of always-on connectivity and sociality. Together they highlight the multiple roles of Chinese-language digital and social media (e.g. WeChat) in the everyday life of "being Chinese," "being Australian" and "being in the world."

Before introducing individual papers of the special issue, we would first explore the two key contested concepts: Chinese digital diaspora and social media. By "diaspora," we mean migrant groups dispersed across socio-cultural-geopolitical boundaries, with a collective memory of and identity associated with the "homeland," the idea of return (not necessarily a commitment to do so, or physical return), and a hybrid consciousness and cosmopolitan disposition (adapting from Brinkerhoff 2009: 31). Migrant communities become diaspora, metaphorically and symbolically, if they no longer feel exclusively identified with the homeland and yet not completely identified with the adopted country even when they have become citizens of their host country. It is the feeling and sense of in-between-ness or hybridity that characterises the state of being "diaspora."

There is a long history of Chinese migration in Australia, dating back as far as the Gold Rush in the $19^{\text {th }}$ century. More recently, the rise of China and the rising number of Chinese migrants in Australia since 2000 have not only changed the composition of Chinese communities but also Chinese-language mediasphere in Australia. The 2016 census shows that there are 1.2 million people of Chinese ancestry in Australia, with $41 \%$ born in the PRC, 
which have outnumbered those of Chinese heritage from Hong Kong, Taiwan, and Southeast Asia individually. Mandarin has become the second largest language spoken at home in Australia. Apart from permanent residents, more than 1.3 million Chinese (excluding children) visited Australia in 2018 (Fang 2019) and another 164,718 Chinese students studying in Australian schools and universities, as of February 2019. ${ }^{1}$ Today people and information cross geopolitical borders at an unprecedented speed, number, and frequency.

Immigration, ethnic media, information and communication technologies, and their implications for Australia are complex phenomena. The rise of China as the world's largest digital economy with the biggest social media market has huge impact on how Chinese view the world and vice versa. Chinese social media landscape is incredibly diverse, rich, and vibrant, with hundreds of active players in the market. China's social media and social commerce platforms - led by those owned by Baidu, Alibaba, and Tencent (aka BAT), joined by a large number of digital unicorns and high-tech start-ups such as ByteDance (known for its AI-based digital news aggregator Toutiao and digital short video platform Douyin/TikTok), iQiyi, Meituan, Didi Chuxing, and Pinduoduo — have not only built up a massive market in China, but also led in spreading Chinese influence overseas, mostly in countries where there are large numbers of Chinese migrants and visitors/tourists, including Australia.

The new Chinese migrants, students, tourists, and visitors often take with them the Chinese ecosystem of social media apps or platforms and continue to rely on these apps as their main platforms for information seeking, social networking, discussing and debating on issue of common concerns, organising events, and shopping and trading. Those who have any kind of interest in the Chinese market, people, politics and society are also drawn to Chinese social media platforms such as WeChat and Weibo, the two pillars of Chinese social media. Chinese migrants in Australia are often spoiled with a wide range of social media platforms, including Facebook, Instagram, YouTube, and Twitter, which are all banned in China. However, Chinese-language digital and social media platforms remain most important and popular among Chinese diaspora in Australia (Sun 2018).

\footnotetext{
${ }^{1}$ https://internationaleducation.gov.au/research/DataVisualisations/Pages/nationalitySummary.aspx
} 
Being digital has become a key feature of contemporary lives. The term "digital diaspora" also known as e-diaspora or virtual diaspora - captures the relationship between technology, digital connectivity, migration, and diaspora. Digital diaspora are organised on the digital and social media platforms; they use the Internet and social media platforms for information (seeking, sharing, exchanging, verifying information of various sorts), networking (to negotiate and consolidate their migrant identity, seek mutual help, and promote solidarity), education (including citizenship education, as they learn, explore, discuss and enact democratic values of the hostland), and organising/mobilising (for economic, cultural, philanthropic and political participation and collaboration in the homeland and hostland) (adapted from Brinkerhoff 2009). A growing body of literature has suggested the Internet has contributed to developing and maintaining the diasporic public sphere (e.g. Everett 2009; Alonso and Oiarzabal 2010;), or in the case of Chinese migrants "a transnational Chinese cultural sphere" (Yang 2003).

From satellite TV to the Internet and social media, technological development has extended a global network within the Chinese diaspora. The Chinese diasporic mediasphere in Australia now consists of websites, various social networking platforms (Internet and mobile based and enabled), newspapers, magazines, TV channels, and radio stations, in both English and Chinese. Since the 2012 release of WeChat (the international version of Weixin, starting since 2011 in China), we have witnessed flourishing Chinese diasporic activities on this super-sticky all-in-one app and mega platform (Chen, Mao and Qiu 2018). As part Facebook, part Twitter, part WhatsApp, part e-commerce, and part of basically anything that is equivalent to an intelligent lifestyle, it allows Chinese immigrants worldwide to tap into networks (old and new) for information, communication, and sociality, with friends and family back in China as well as new friend and business networks in their host countries and around the world.

An important feature of WeChat is its public accounts, ${ }^{2}$ first launched in 2014 , which allow any individual or collective entity to reach their subscribed audience or readers on their mobile phones on a regular basis. WeChat news public accounts have eclipsed Chinese-

\footnotetext{
2 There are two kinds of public accounts on WeChat: subscription account and service account. The former is nested in a folder, while the latter appears in the same way as one's friends on WeChat. The vast majority of businesses, organisations and individuals use subscription accounts as they can publish timely information every day, while a service account can send only four messages per months.
} 
language newspapers in providing timely news content at people's fingertips. Chineselanguage media in Australia have already gone through transformations that are increasingly reader-friendly to PRC migrants in format, language, and content (Sun 2016). Most of the Chinese-language newspapers have gone online, with a website and a WeChat public account. There are also hundreds of Chinese-language public accounts on WeChat-only on WeChat - that provide local news and information to target the new Chinese migrants in Australia who, unlike the older generations, are younger, educated, cosmopolitan, and digital. These sites and accounts are primarily operated by Chinese migrant entrepreneurs. They focus on lifestyle issues and often translate, edit and synthesise news from Australian and Chinese media outlets, often through their own editorial lens.

Clearly, the diasporic mediasphere is complex and stratified. Similarly, Chinese migrants in Australia are also diversified and divided. They are differentiated by origin, dialect, migration history, level of English proficiency, socioeconomic status and political allegiance (Sun, Fitzgerald \& Gao 2017), apart from the usual human variables such as age, gender, education, and citizenship. Their media production and consumption practices are equally complex and diversified. Their activities on and around digital and social media can have implications for the migration and integration process, identity negotiation and formation, and public policy on multicultural citizenship in the host country.

This special issue includes four original articles that analyse the roles of digital and social media in the lives of Chinese digital diaspora in Australia. It engages with questions on (1) the ways and extent that these digital platforms and practices can create new forms of civic engagement and enable Chinese migrant communities to participate in public life in Australia; (2) the impact of such digital and mobile communication practices on their socioeconomic, cultural and political lives in Australia as multicultural residents and citizens.

Wanning Sun's article uses examples of Sydney Today (the most popular and widely read Chinese-language digital media outlet in Australia, with a website and a WeChat public account), to discuss the challenges facing Australia in its attempt to engage diasporic media for the purpose of public diplomacy towards China. Based on a pilot study, the paper first reviews some of the major developments in the Chinese-language media in Australia, paying particular attention to the key features of digital/social media since the arrival of PRC migrants. It then presents examples from four key content categories: Australia-China 
relations, politics, economics and cultural life. Finally, the paper identifies the challenges and opportunities facing Australia's public diplomacy towards China, and outlines some key methodological and analytical framework for future research.

While Sun's article highlights the role of Chinese-language digital and social media in the public life and public diplomacy of being Chinese-Australians, Xinyu Zhao's article adds a more mundane and everyday dimension to the role of such platforms among Chinese international studies living in Australia and focuses on the intersections of transnational student migration and everyday digital sociality. It highlights the social media practices of Chinese overseas students in Australia who seek to not only maintain intimacy and closeness with their parents and significant others in China, but more importantly, to manage the familial relationships to the extent that they are comfortable with through the tactical practices of social media platforms including WeChat. Zhao's article contributes to the literature on transnational family arrangement in the digital age by providing an insight into the micro-politics of mediated co-presence through the trope of 'disconnective practice'.

The third article by Ge Zhang and Wilfred Wang continues to examine Chinese social media, represented by WeChat, in the everyday life among Chinese migrants in Australia, particularly through their interest in and talks about the Australian property market. It focuses on how migrant social media and real estate professionals' narratives on real estate properties constitute and reproduce a transnational Chinese diasporic space between China and Australia. Talking about land and property ownerships has always been integral part of Chinese diasporic culture, which has been delivered, processed and experienced through digital platforms such as WeChat. The paper argues that WeChat's informational, interpersonal, and instrumental affordances have aided Chinese migrants and Chinese real estate practitioners to co-constitute a social space of property talk that enables new social relations to be negotiated, social networks to be established and reinforced across China and Australia.

The fourth article by Haiqing Yu and Hayden Blain takes us to the interactions of the intimate space and the national space on and off social media platforms that include both Chinese and non-Chinese ones. It focuses on the placemaking experience of first-generation young tongzhi/gay migrants from China, as they struggle to negotiate their cultural and sexual identities in Australia. Tongzhi is used as a lingua-cultural reference to their double identity as Chinese and gay. In particular, it investigates their negotiations with Chinese and 
homosexual identities online via social media and offline via gay encounters as they migrate to Australia and have intercultural contact with Chinese and non-Chinese (gay) communities in Sydney and Melbourne. Drawing from formal interviews and personal communications with Chinese gay men who initially arrived in Australia on student visas from 2015 to 2017, this article explores how these tongzhi migrants use digital/social media to reconstitute their home abroad and to live out their transnational gay identity, politics and desire. Their placemaking practices take place in the intersections of the Internet and outernets (the network of social, cultural, and economic relationships that criss-crosses and exceeds social media and the Internet), as well as the interzones of one's gay desires for sexual fulfilment and cultural empowerment.

The special issue is among our first interventions into the questions around the increasing influence of Chinese-language digital and social media in Australia and around the world. The four articles in the special issue have examined WeChat and other Chinese-language digital and social media as a public space (Sun), private and intimate space (Zhao; Yu and Blain), and business and networking space (Zhang and Wang). They have not only examined the relation between Chinese diaspora's engagement with social media (both Chinese and international) and their sense of being Chinese, being Australian, and being in the world; but also raised more questions that cannot be answered by this special issue alone.

The growing importance of social media among the Chinese diaspora calls for detailed and systematic inquiry into the implications of this development for Australia's multicultural policy, social cohesion and effective engagement with China. WeChat and other Chineselanguage social media apps on people's smart phones constitute an essential part of them being Chinese living in Australia. Chinese digital diasporas have been known to use digital and flexible means to communicate, network, and organise among and beyond themselves, in and beyond their host countries. We hope that this special issue will encourage more nuanced research to follow, and that the Australian experience will shed light on the debate and scholarship about transnational China, Chinese diasporic media, and migration and multiculturalism in the era of digital/social media.

\section{References:}

Alonso A and Oiarzabal P (eds.) (2010) Diasporas in the New Media Age. Reno, NV: University of Nevada Press. 
Brinkerhoff JM (2009) Digital Diasporas: Identity and Transnational Engagement. Cambridge, UK: Cambridge University Press.

Chen Y, Mao Z, and Qiu JL (2018) Super-sticky WeChat and Chinese Society. Emerald Publishing, 2018.

Fang J (2019) Chinese tourism boom could slow down if Australia becomes complacent, expert warns. ABC, 16 Jan. Available at: https://www.abc.net.au/news/2019-0126/warnings-not-to-be-complacent-with-chinese-tourism-market/10746516

Sun W (2018) How Australia's Mandarin speakers get their news. November 22. http://theconversation.com/how-australias-mandarin-speakers-get-their-news-106917

Sun W (2016) Chinese-language media in Australia: developments, challenges and opportunities. Australia-China Relations Institute. Available at: https://www.australiachinarelations.org/content/chinese-language-media-australiadevelopments-challenges-and-opportunities-2

Sun W, Fitzgerald J, and Gao J (2017) From multicultural ethnic migrants to the new players of China's public diplomacy. In: Wong B and Tan CB (eds) China's Rise and the Chinese Overseas. London and New York: Routledge, pp. 55-74.

Yang G (2003) The Internet and the Rise of a Transnational Chinese Cultural Sphere. Media, Culture \& Society 25(4): 469-490. 